\title{
Failure Analysis of Cracks Formed at Extrados of Bend Pipe of API 5L X65M Grade
}

\author{
J. Raghu Shant • Bijay K. Pandey • \\ Rajesh K. Goyal • T. S. Kathayat
}

Submitted: 10 September 2012/in revised form: 21 January 2013/Published online: 13 July 2013

(C) The Author(s) 2013. This article is published with open access at Springerlink.com

\begin{abstract}
A metallurgical and root cause analysis was performed on hot induction bent pipes that exhibited cracking at the extrados. The bent pipe of $1016 \mathrm{~mm}$ (40 in.) diameter by $18.5 \mathrm{~mm}$ wall thickness was API $5 \mathrm{~L}$ X65 PSL2 line pipe containing a longitudinal submerged arc weld. A metallurgical cross section was removed at a crack on the bent pipe extrados to document the crack morphology using optical microscopy. In addition to the cracking, golden-yellow streaks were visible at the extrados of the bent pipe. The composition of the streaks was examined using scanning electron microscopy with energy dispersive spectroscopy.
\end{abstract}

Keywords Cracks - Hot induction bending ·

LSAW pipes · Copper diffusion

\section{Introduction}

Sixteen bends out of 139 bends of $1016 \times 18.5 \mathrm{~mm}, \mathrm{X} 65$, and $3 \mathrm{D}$ radius have been observed with cracks at the extrados. The cracks were observed perpendicular to the bend/pipe axis (Fig. 1). Tables 1 and 2 give a gist of the chemical composition and process parameters of bends

J. R. Shant $(\bowtie) \cdot$ B. K. Pandey · R. K. Goyal · T. S. Kathayat Welspun Corp Ltd, Anjar, Kutch, Gujarat, India

e-mail: raghu_shant@welspun.com; raghushant@gmail.com which have failed during bending operation in two bending machines. After UT inspection of the cracks, a depth of approximately $10-15 \mathrm{~mm}$ was found with a length approximately in the range of $2-10 \mathrm{~mm}$. The cracks were observed on bends formed at both bending machines.

\section{Chemical Composition}

Metallographic Analysis

A couple of bend samples were taken for metallographic analysis as a representing one for the cracks formed on the bends at the extrados location. The cross section of the crack was microscopically analyzed in the unetched and etched conditions. The clear presence of golden-yellow color particles seen in the unetched condition indicates the entrapment of the foreign particles in the crack vicinity. After etching the sample, the presence of copper is observed at the grain boundary. This shows the possibility of copper diffusion during pipe bending at high temperature (Fig. 2).

\section{SEM-EDS Analysis}

The crack samples were subjected to SEM-EDS analysis to insure the presence of copper at the grain boundary (Fig. 3). EDS spectra show the prominent peaks of copper entrapment at grain boundaries in the cracked region. The white particle shows the presence of copper at the grain boundary in the crack vicinity. An SEM image has been taken in the backscattered image mode in order to resolve the copper presence. 

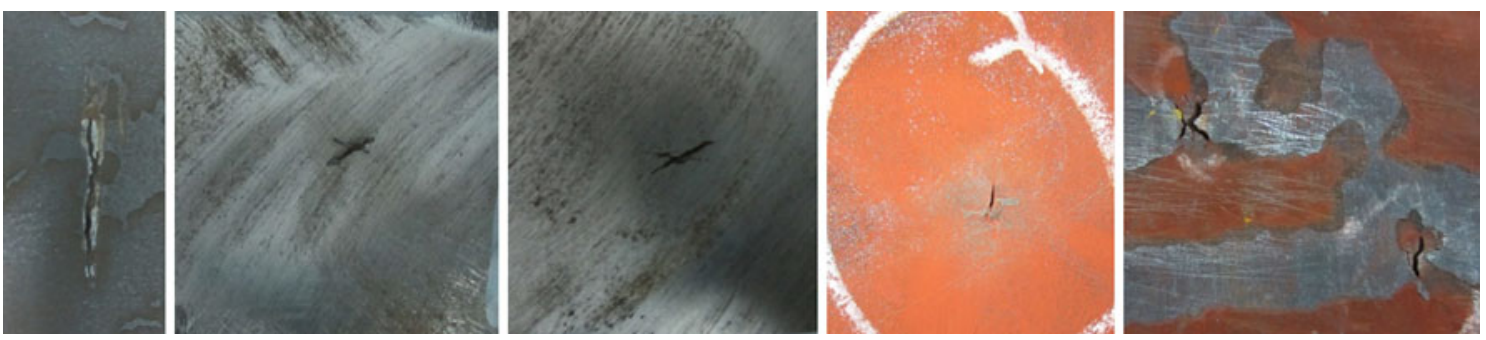

Fig. 1 Crack photos observed on the extrados portion of the bend

Table 1 Chemical composition of the bends (\%)

\begin{tabular}{ccccccccccccccc}
\hline $\mathrm{C}$ & $\mathrm{Si}$ & $\mathrm{Mn}$ & $\mathrm{P}$ & $\mathrm{S}$ & $\mathrm{Al}$ & $\mathrm{Cr}$ & $\mathrm{Cu}$ & $\mathrm{Ni}$ & $\mathrm{Mo}$ & $\mathrm{Ca}$ & $\mathrm{N}$ & $\mathrm{B}$ & $\mathrm{AL} / \mathrm{N}$ & $\mathrm{V}+\mathrm{Nb}+\mathrm{Ti}$ \\
\hline 0.07 & 0.24 & 1.43 & 0.008 & 0.0030 & 0.036 & 0.23 & 0.016 & 0.011 & 0.22 & 0.003 & 0.0045 & 0.0002 & 8.0 & 0.10 \\
\hline
\end{tabular}

Table 2 Parameter details of 16 bends formed in different machines

\begin{tabular}{lllll}
\hline & \multicolumn{3}{c}{ Bending parameter } \\
\cline { 2 - 4 } S1 No. & Temp $\left({ }^{\circ} \mathrm{C}\right)$ & Speed $(\mathrm{mm} / \mathrm{min})$ & Water flow $\left(\mathrm{m}^{3} / \mathrm{h}\right)$ & $12.82-12.95$ \\
\hline 1 & $966-978$ & 10 & $13.50-13.95$ & Machine No. \\
2 & $970-988$ & 11 & $13.28-13.52$ & 1 \\
3 & $968-973$ & 11 & $13.76-13.85$ & 1 \\
4 & $961-985$ & 11 & $45.10-45.21$ & 1 \\
5 & $990-994$ & 20 & $44.64-45.36$ & 2 \\
6 & $978-990$ & 20 & $46.1-46.32$ & 2 \\
7 & $984-995$ & 20 & $45.70-45.98$ & 2 \\
8 & $982-999$ & 20 & $44.12-44.92$ & 2 \\
9 & $978-1003$ & 20 & $44.80-46.04$ & 2 \\
10 & $972-997$ & 20 & $45.04-45.25$ & 2 \\
11 & $972-1005$ & 20 & 46.00 & 2 \\
12 & $972-1006$ & 20 & $44.12-44.21$ & 2 \\
13 & $976-993$ & 20 & $44.04-44.21$ & 2 \\
14 & $985-995$ & 20 & $44.21-44.51$ & 2 \\
16 & $978-995$ & 20 & 20 & 2
\end{tabular}

\section{Copper Entrapment in the Steel}

The golden-yellow color particles could be either copper or a copper alloy as shown by the optical and SEM microphotographs. The diffusion of copper (melting point $1080{ }^{\circ} \mathrm{C}$ ) in to the grain steel boundaries was the reason for the cracks on the bend extrados surface. Copper diffusion weakens the austenite grain boundary at $\sim 980{ }^{\circ} \mathrm{C}$ (bending temperature). The weak austenite grains are no longer strong enough to sustain the tensile forces experienced by the bend extrados and hence a generation of cracks mostly transverses to the pipe axis. These cracks get opened up during subsequent stress-relieving heat treatment of the bends. A change in the cracks' morphology could be due to variation in the level of the copper entrapment on the surface of steel. A crack propagation model was discussed as shown in Fig. 4 [1]. The model consisted of three elementary factors: They were low melting metal or alloy, high temperature, and tensile stress, which would most likely lead to crack initiation. Firstly, the low melting metal or alloy contacted or attached to base metal before forming as shown in Fig. 4a. Secondly, the low melting metal or its alloy met the high temperature of nearly $1000{ }^{\circ} \mathrm{C}$ during the induction heating, at which point the low melting metal or alloy got into active materials and began to melt and evaporate at the attached point; at the same time that the surface tension was decreased, the attached area spread. 


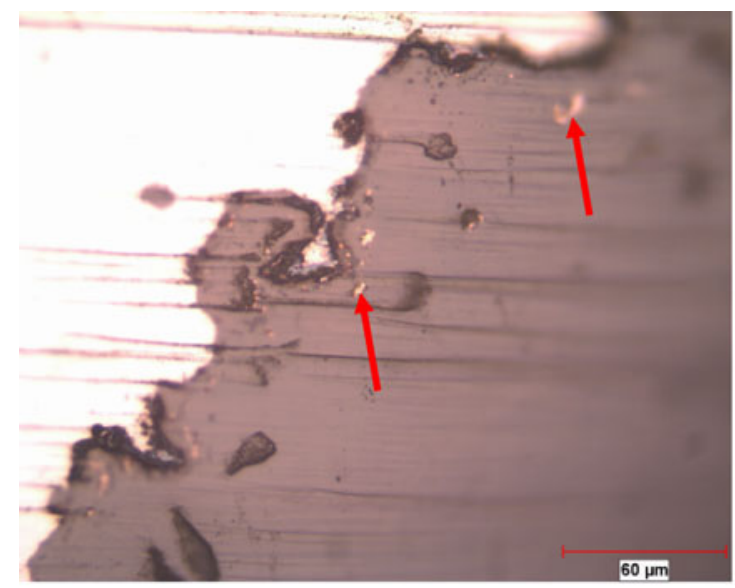

(a) Un-etched section showing golden yellow copper in crack vicinity $500 \mathrm{X}$

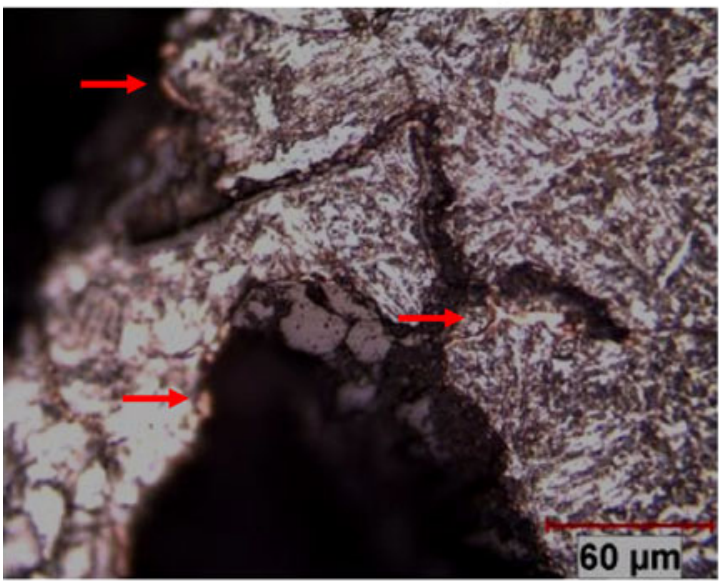

(c) Etched section showing copper at grain boundary $500 \mathrm{X}$

Fig. 2 Microphotographs of cracks in unetched and etched conditions

The low melting metal/alloy diffused into base metal as greater concentration gradient existed at the interface of low melting metal/alloy and the base metal. Meanwhile, at the austenite transformation point, the austenite was formed and the diffusions progressed away along the grain boundary deep into the base metal. Thirdly, the outside of the bent pipe elbow was subjected to tensile stress during the forming process, while the permeated and diffused low melting metal or its alloy could hardly be subjected to the stress at the high temperature. Normally, the low melting metal or its alloy began to soften at the range of $500-900{ }^{\circ} \mathrm{C}$ and could not carry over and bear the tensile stress at all, at which the source of the crack was formed and cracked along the grain boundary, as show in Fig. 4c. Besides, the tensile stress promotes and accelerates the low melting metal or its alloy to diffuse into the base metal, so that the new crack tip was formed and began to travel and spread, as shown in Fig. 4d, e.

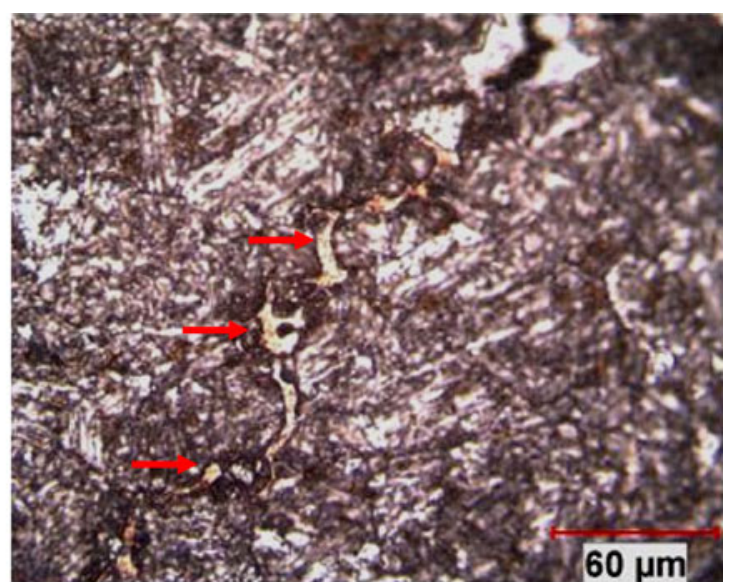

(b) Etched section showing copper at grain boundary $500 \mathrm{X}$

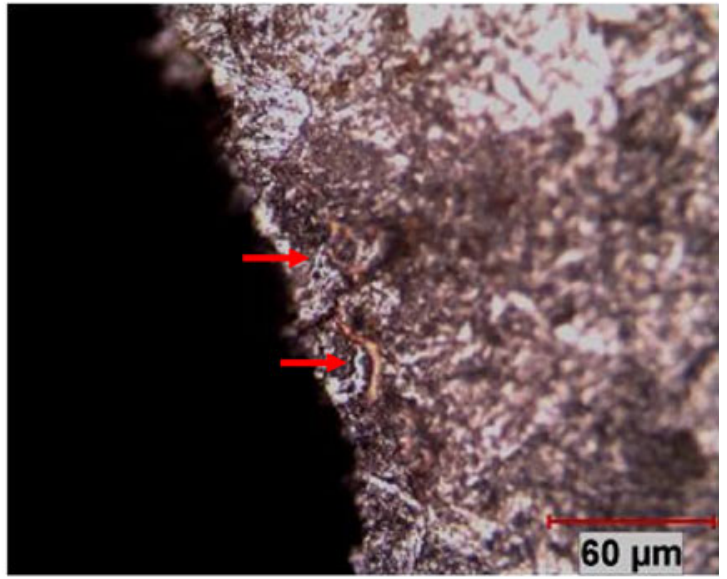

(d) Etched section showing copper at grain boundary $500 \mathrm{X}$

However, another theory suggests that since iron oxidizes more easily than copper, the preferential oxidation of iron on the surface causes copper enrichment during induction heating [2]. The enriched phase becomes liquid over a certain temperature. Liquid copper penetrates into austenite grain boundaries and weakens grain boundaries, leading to a loss of ductility. The cracks appear on the external arc of the tensile region during pipe bending as the strain and stress of this place are higher than that of the other place. In order to decrease the cracks ratio, it is necessary to strictly control the heating temperature during bending. Copper, being the key element related to surface defects of steel, is one kind of residual element. Copper is very difficult to be remove during steelmaking as the oxidation of copper is more difficult than that of iron. Surface hot shortness is a processing problem that can affect steels containing only few tenths of a percent of copper. Heating 
Fig. 3 SEM and EDS microphotograph (backscattered image mode) (white particle of copper in matrix of steel and its oxide)

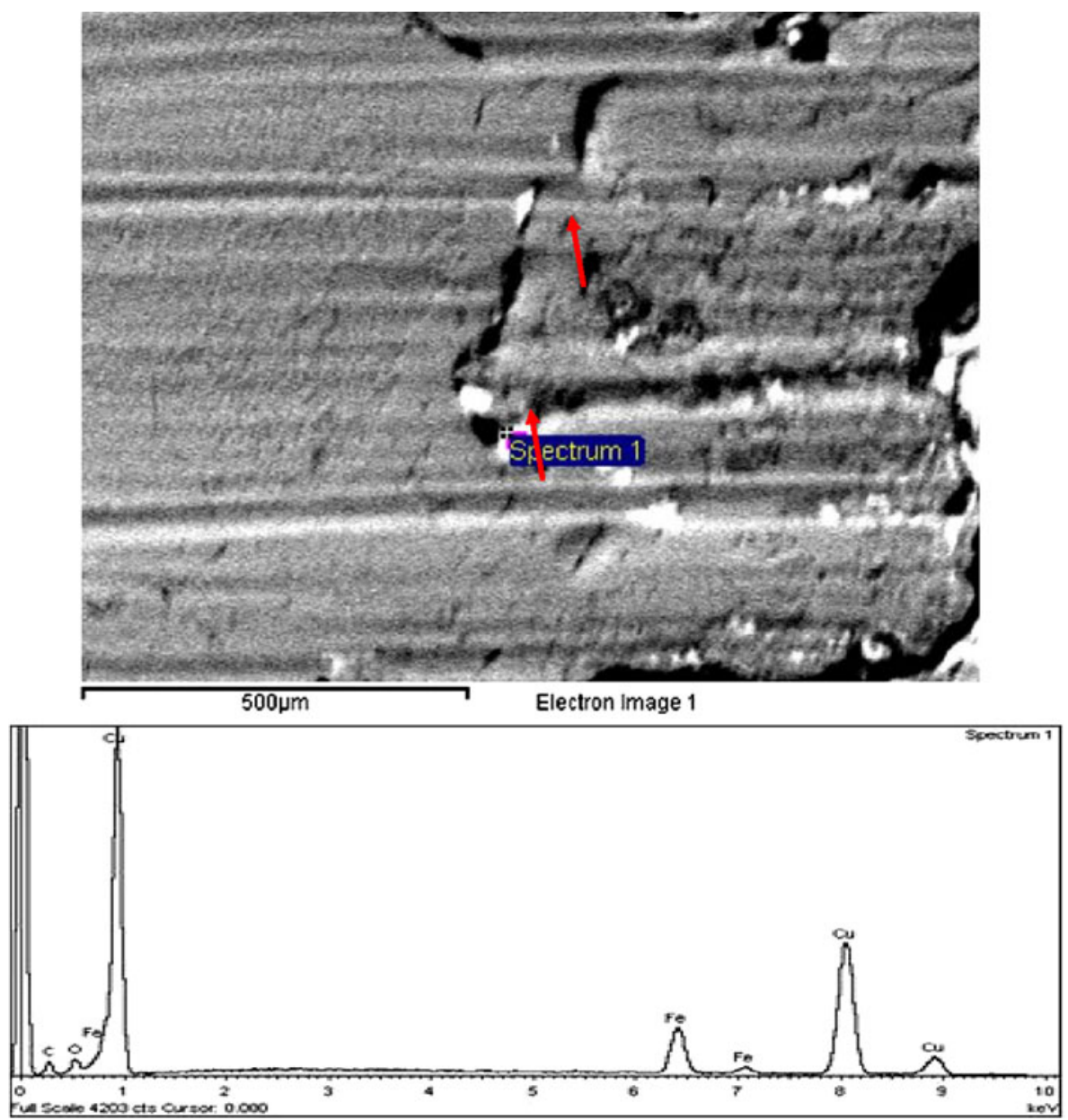

temperature is a crucial parameter during induction heat bend pipe. Loss of ductility caused by copper mainly appears in the temperature range $1050-1200{ }^{\circ} \mathrm{C}$ as the enriched phase becomes liquid over $1090{ }^{\circ} \mathrm{C}$. In order to decrease the cracks ratio, it is necessary to strictly control the heating temperature during bending.

The effect of copper from chemical composition is debatable as cracks are formed randomly at the extrados in the present investigation. Bends with higher amounts of copper in chemical composition should form cracks throughout the bend extrados as the whole extrados is subjected to higher stain and stress; however, the cracks are formed with lower bend temperature and randomly on the extrados.

\section{Sources of Copper/Copper Alloys}

There are three prominent possibilities of copper entrapment in steel, plates, and pipe manufacturing as shown in Fig. 5:

a. Copper molds used during continuous casting stage

b. During pipe manufacturing at JCOE

c. Induction coil used in hot induction bending (HIB)

\section{Copper Molds Used During Continuous Casting Stage}

The copper entrapment in the steel during the continuous casting (Fig. 6) stage from the water-cooled copper mold is ruled out in the present investigation. If copper was entrapped in the steel during continuous casting, then cracks would have formed at the slab narrow or broad face which would further create a crack in the plate. However, no cracks were reported while plate rolling or during pipe manufacturing.

\section{During Pipe Manufacturing at JCOE}

The $\mathrm{Cu}$-alloy plates used on entry side skids and the copper blocks used inside the lower die of the JCO mill may be the potential sources for copper to get stuck on and embedded into the pipe surface during pipe forming. The steel plate is skidded through the $\mathrm{Cu}$-alloy plates and the pipe is pushed up by copper blocks during the forming operation (Fig. 7).

\section{Induction Coil in Bending}

There is a far remote possibility of copper entrapment from the copper induction coil used for heating during bending. 
Fig. 4 Schematic diagram of the copper entrapment in the steel [1]

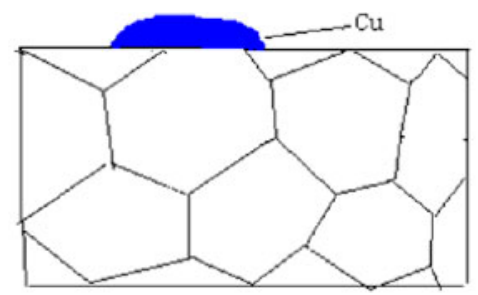

(a) Low melting metal or alloy attached to base metal

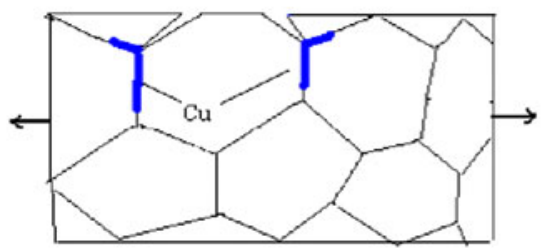

(c) Tensile stress lead to initial crack

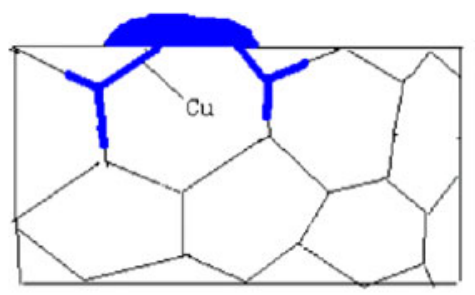

(b) Permeate and diffuse

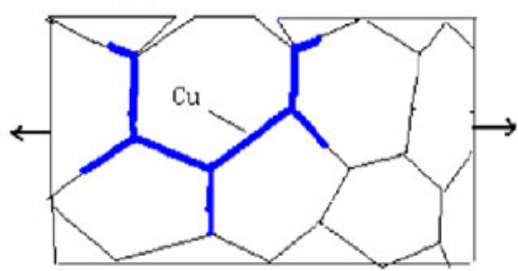

(d) Tensile stress promote permeate and diffuse

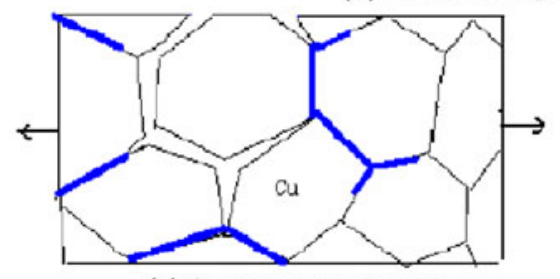

(e) Crack spread and travel

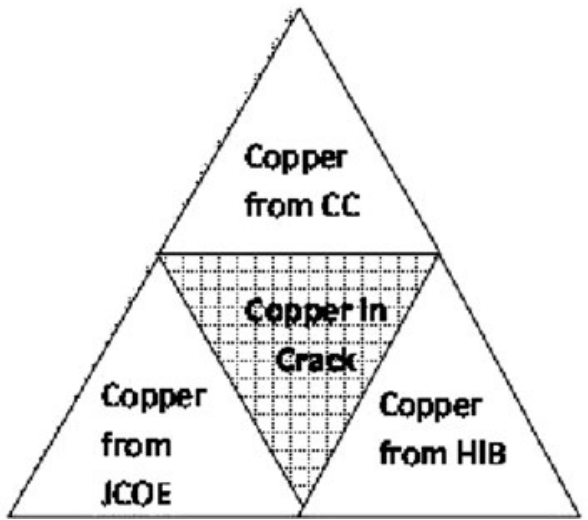

Fig. 5 Prominent possibilities of copper entrapment

Approximately $\sim 25 \mathrm{~mm}$ distance is maintained between the induction coil and the steel surface. Further, there is air pressure which will wipe out any particles falling on the hot annular ring if any cooper flakes off from the induction coil. The induction coil (Fig. 8) is cooled from the inside by circulation of de-mineralized water and hence temperature will not cross the prescribed limit.

Final Identification of Copper Source

The pipes received from the LSAW plant were thoroughly inspected and the copper-alloy streaks were found on the

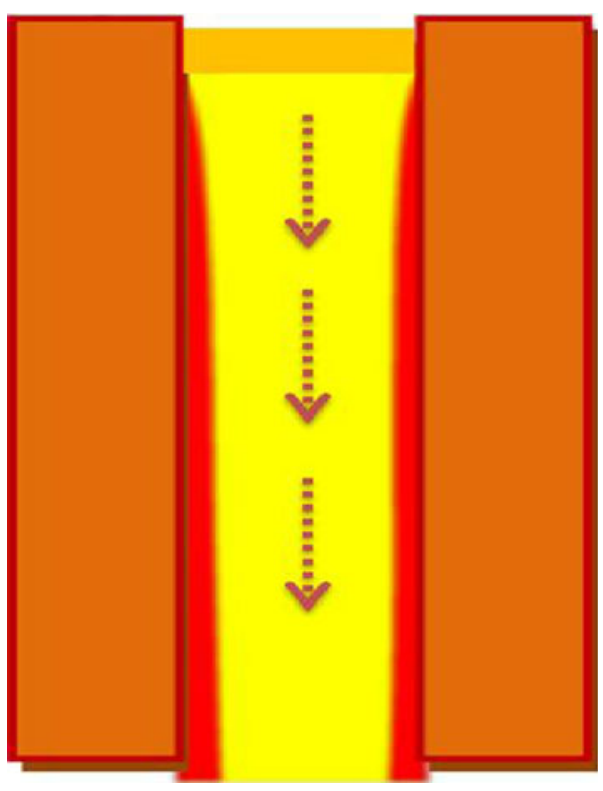

Fig. 6 Water-cooled $\mathrm{Cu}$ Mold

pipe OD surface in the transverse direction mostly and occasionally in the longitudinal direction of the pipe axis (Fig. 9).

The pipe OD surface which corresponds to the plate's bottom surface comes in contact with the $\mathrm{Cu}$-alloy plates 
Fig. $7 \mathrm{Cu} / \mathrm{Cu}$-alloys used during JCOE forming
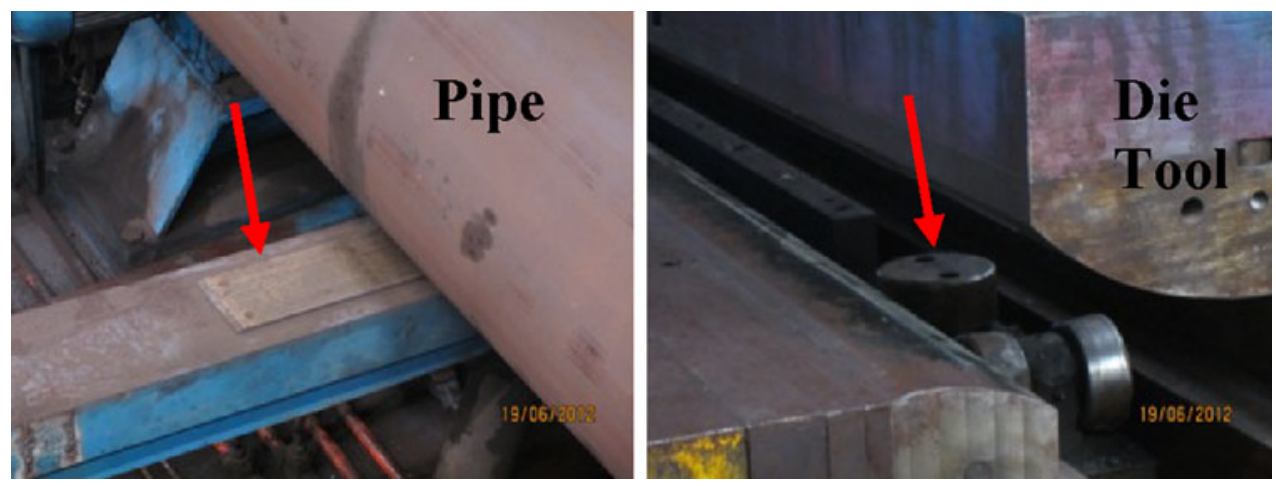

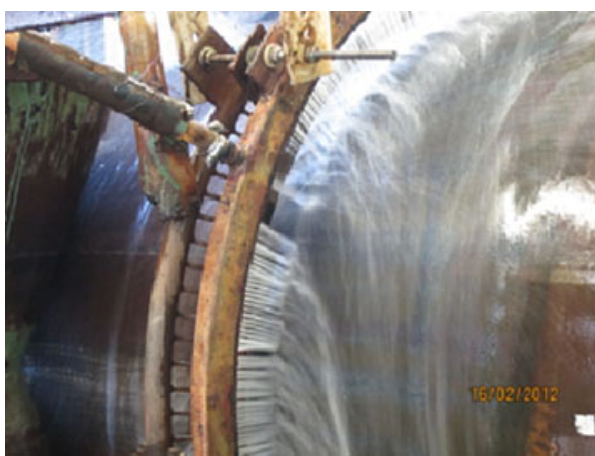

Fig. 8 Induction coil of copper

used at the JCO mill. The plate is entered in the transverse direction and occasionally there is some longitudinal movement of the plate or pipe while forming in the JCO mill. The Cu-alloy plates used in the JCO mill were also found in wear condition as shown in Fig. 10. The presence of oil/ grease on these plates will help the small pieces of $\mathrm{Cu}$-alloy to get stuck on the plate surface. These small pieces of $\mathrm{Cu}$-alloy will get pressed in and embedded during pipe forming and appear as $\mathrm{Cu}$-alloy streaks on the pipe OD surface.

\section{Conclusions}

The pipe received from the LSAW plant with $\mathrm{Cu}$-alloy streaks on the pipe OD surface has led to the copper diffusion at the grain boundary during HIB operation at $\sim 980{ }^{\circ} \mathrm{C}$. The copper being a low melting point metal weakens the austenite grains which get disintegrated in the form of transverse cracks due to hot shortness and tensile
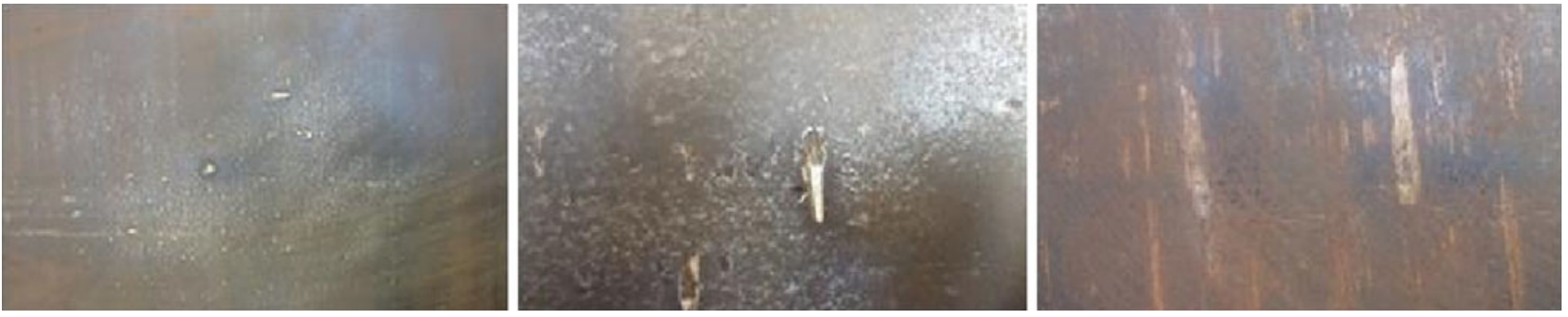

Fig. 9 Golden-yellow color copper-alloy streaks on pipe OD surface

Fig. $10 \mathrm{Cu}$-alloy plates in wear condition at JCO mill
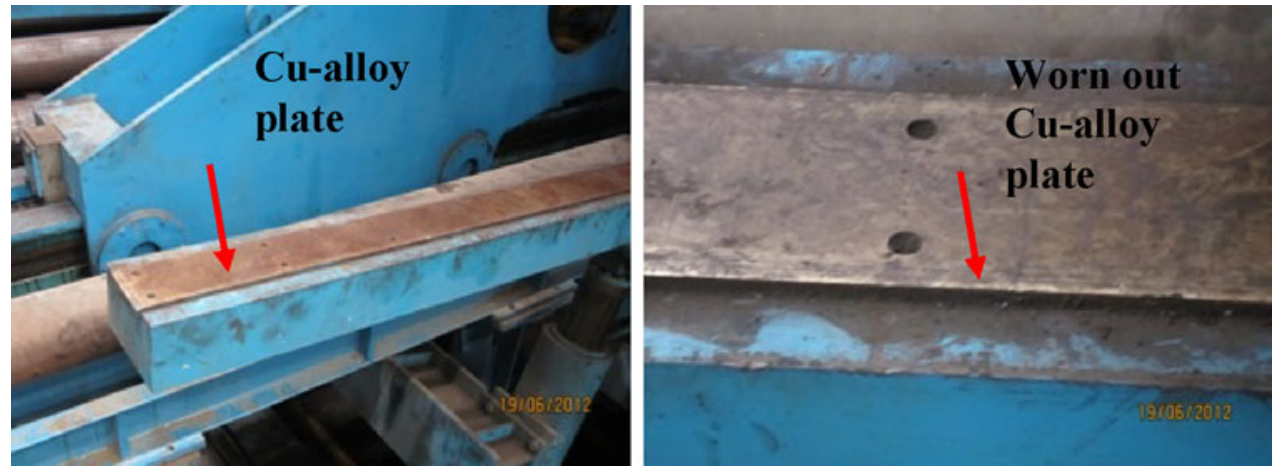


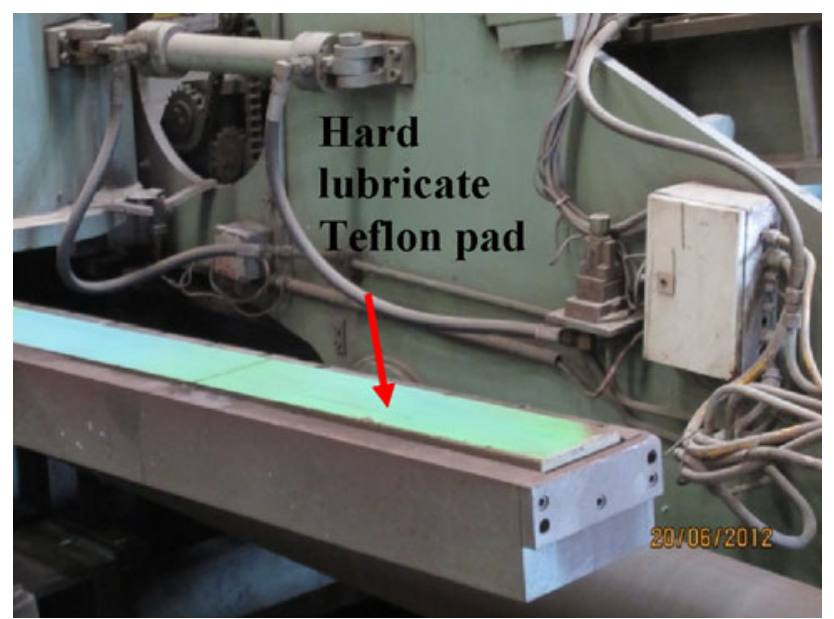

Fig. 11 Hard lubricated teflon pads

forces at the bend extrados portion. These small cracks got opened up during subsequent stress-relieving heat treatment of bends, and the cracks were clearly visible on the bend extrados portion. Ultimately, the bend with cracks got rejected.
The use of hard lubricated Teflon pads as shown in Fig. 11 is a better option in place of Cu-alloy plates used at the JCO mill to avoid any copper entrapment. After adopting hard lubricated teflon pads at the entry side skids, bends were manufactured from the LSAW pipes and no cracks developed during bending operation.

Acknowledgments The authors are thankful to the Welspun Corp management for giving their support and permission to prepare and publish this paper.

Open Access This article is distributed under the terms of the Creative Commons Attribution License which permits any use, distribution, and reproduction in any medium, provided the original author(s) and the source are credited.

\section{References}

1. Z. Yang, D. Liu, X. Zhang, Appl. Mech. Mater. 29-32, 697-702 (2010)

2. L.J. Li, X.D. Huo, L. Guo, Adv. Mater. Res. 430-432, 229-232 (2012) 